\title{
Discurso e expressão nos estudos da linguagem
}

\section{Paulo Juarez Rueda Strogenski - Mestre em Lingüística - Professor da UTFPR}

paulojrs@cefetpr.br

Resumo:

A tradição científica ocidental elegeu um tipo de discurso já canonizado que determina como deve ser comunicação dos estudos científicos, o que acaba por determinar limites muito estreitos na comunicação dos estudiosos das diversas áreas. Especificamente nos estudos da linguagem, talvez não seja esse o formato mais adequado para que o estudioso possa expressar o seu pensamento sobre a riqueza da linguagem, porque acaba também por "engessar" a forma como se pensa a linguagem.

Palavras-chave: linguagens, ciências, teorias lingüísticas, discurso, ensaio.

No âmbito dos estudos da linguagem muito se discute sobre o estatuto da Lingüística enquanto ciência. O fato de pretendê-la como ciência acaba por criar vários problemas para aqueles que pretendem estudar a linguagem de um ponto de vista, digamos, menos "controlado", entendendo essa expressão não como uma crítica a esse tipo de abordagem, mas como uma tentativa de compreender a angústia daqueles que entendem controle como reducionismo. Em virtude da controvérsia que surge entre aqueles que defendem um reducionismo indispensável para o fazer científico e os que preferem adotar um ponto de vista mais metafísico para encarar a linguagem, existe um desafio hoje no âmbito da epistemologia da Lingüística diretamente ligado ao problema de se incluir o falante e a fala no estudo da linguagem, mas sem perder de vista o que é próprio da língua. Em última análise: incluir o imprevisível na ordem.

Isso acaba por causar um grande problema para as teorias lingüísticas que pretendam dar conta de um número maior de fatos da linguagem, já que a análise dos dados exige sempre que se faça um recorte. No título de seu texto (O dado dado e o dado dado, Possenti (1996) "brinca" com a palavra DADO para demonstrar como em ciência esta palavra pode ter um duplo sentido - se não semanticamente, pelo menos ideologicamente, filosoficamente, heuristicamente ou, em última análise, intencionalmente. Ideologicamente porque o dado pode ser escolhido para comprovar determinadas ideologias (principalmente, na análise do discurso (e através dela)); filosoficamente porque a filosofia da ciência nos ensina que em essência é a teoria que determina a realidade, ou seja, a teoria determina a natureza e a validade do dado; heuristicamente porque a escolha dos dados faz parte das estratégias de trabalho das ciências na busca da "verdade", o que depende da intenção do cientista.

No caso da análise do discurso francesa, por exemplo, o analista acaba por se debruçar sobre um tipo de dado que é mais facilmente analisável e manipulável: o dado proveniente de 
uma linguagem institucionalizada, fortemente marcada por um caráter ideológico e mais ou menos estável em relação aos usos e às estratégias discursivas. É o dado rentável, aquele que serve basicamente para confirmar as hipóteses originais da teoria.

Segundo Sírio (e faço minhas as suas palavras), a AD "deveria debruçar-se hoje sobre o dado mais próximo possível da linguagem ordinária" (p.199). Este dado é daquele tipo capaz de colocar uma teoria em xeque, forçando-a, de fato, a demonstrar o seu poder de análise. Na sua nomenclatura, é o dado crucial.

Em geral, o dado crucial é deixado de lado pela AD que prefere "redizer o dito" (p.200) ao reafirmar sempre aquilo que já foi comprovado através do uso de um material estrategicamente escolhido para cumprir esse objetivo, o que no mínimo trata-se de uma maneira reducionista e tímida de enfrentar a grandiosidade do processo discursivo.

Claro que é a maneira usual como as ciências, e a própria lingüística, enfrentam o desafio de explicar a realidade: recortando-a e confinando-a aos limites que a teoria permite, desprezando toda realidade que não seja a realidade teórica, esquecendo, ou deixando de lado, que existe uma realidade não científica (ou não Filosófica) na qual todos estamos imersos, até mesmo as teorias que, essencialmente, são um tipo de linguagem e elaboradas através da linguagem. Uma linguagem que, ao contrário do que muitos cientistas acreditam, não é caótica; muito diferente disso, é uma linguagem que, por mais "ordinária" que se diga, é definida por regras de regularidade e compartilhada por uma sociedade de indivíduos que produzem seus discursos, pasmem, até mesmo em ambientes não institucionalizados e, exatamente por isso, desprezados pela $A D$.

Em relação ainda ao discurso (ou, mais ou menos, no âmbito da Lingüística Textual), podemos exemplicar a questão da escolha de dados, verificando como um recorte se faz a partir de uma hipótese básica, através das idéias de Deleuze e Guatari (1995). Para eles, "a primeira determinação que preenche a linguagem é o discurso indireto", o que contraria a tese tradicional de grande parte dos estudos da linguagem que observam os atores da conversação de que a linguagem tem como seu objetivo fundamental comunicar algo de um indivíduo para outro: um primeiro que seria a fonte do dizer, a testemunha de um fato, que o traduziria em linguagem, para depois transmitir a mensagem para um segundo, um receptor da mensagem, capaz de decodificar a linguagem e que, a partir desse momento, tornar-se-ia co-testemunha do fato narrado pelo primeiro. A proposta de Deleuze e Guatari coloca o primeiro já como testemunha auditiva do fato e não como testemunha visual; auditiva no sentido de que o primeiro já ouviu falar, já leu, já foi informado sobre o fato, sem o presenciar diretamente. Quando falamos sobre um fato do real, como um livro, por exemplo, já falamos sobre um real traduzido em linguagem pelo autor do livro, o qual, por sua vez, mesmo que esteja falando sobre o real, o traduziu em linguagem e estará narrando sobre o real. Mais radicalmente, mesmo quando estamos falando de um fato que presenciamos, narramos, assumimos uma postura de narrador e colocamo-nos como personagens de nossa própria história. Por mais sinceros que sejamos, não o seremos absolutamente porque o fato será passado para o outro pela linguagem e esta jamais será isenta. Para eles, o discurso é e só pode ser originalmente indireto porque é o 
resultado de um fazer coletivo. A grande massa discursiva seria então composta de discursos indiretos, ou talvez um grande discurso indireto, fruto do compartilhamento de um acordo coletivo aceito pela comunidade. Desse discurso indireto coletivo, cada qual poderia extrair o seu discurso direto individual, ou seja, do coletivo se originaria o individual e não o oposto, como tradicionalmente sugerido. Essa postura coloca o discurso indireto em posição determinante para a linguagem, deixando em segundo plano o papel dos tropos, porque "a importância que se quis dar à metáfora, à metonímia, revela-se desastrosa para o estudo da linguagem".

Ao contrário deles, Nietzsche defendia que a linguagem faz uso das figuras (tropos) para criar as imagens com as quais os impulsos são exteriorizados, o que quer dizer que a linguagem jamais expressaria algo em sua totalidade, mas apontaria, através das figuras (sinédoque, metáfora, metonímia), algum aspecto relevante capaz de diferenciar esse algo de outros algos. A diferença entre as duas posturas parece estar no como o Ser se relaciona com o mundo através da linguagem: no primeiro modelo a linguagem parte do coletivo, através do discurso indireto, para se particularizar no Ser e depois retornar ao coletivo como um acréscimo a esse coletivo que será novamente particularizado e "coletivizado" num constante devir da linguagem; já no segundo modelo, a linguagem partiria do como o Ser interpreta o mundo através da linguagem e o expressa através dos tropos para o coletivo, num constante "jogo" de exposição e ocultação em relação aos outros seres.

Partindo disso, retornemos ao início do texto, quando foi citado o problema do controle dos dados do qual se infere a determinação de que a Lingüística, para se pretender ciência, só poderia estudar a linguagem a partir de uma noção de homogeneidade, de um sistema homogêneo e estável - muito diferente da língua real, heterogênea e instável, muito diferente de uma linguagem como a vista no parágrafo anterior. Homogeneização que se faz através de um modelo científico que nada mais é do que um modelo político em essência: a Lingüística é o que é porque nasceu e proliferou em um meio político republicano (França, Estados Unidos) moldado por critérios positivistas. Se a Lingüística houvesse nascido em um ambiente socialista, marxista, com certeza seria diferente - talvez melhor ou talvez pior em relação à definição do objeto para o estudo da linguagem, mas com certeza diferente. Um modelo como o de Chomsky, que tenta buscar constantes universais que seriam a origem das variantes jamais seria capaz de dar conta de uma linguagem como a entendida por Deleuze e Guattari (ou por Nietzsche), que invertem o ponto de vista sobre a relação constante - variante porque, segundo sua concepção, o uso das variantes é que cristalizaria as constantes, ou ainda, as línguas menores (dialetos, idioletos) definiriam as línguas ditas maiores, o quer dizer que não haveria uma língua padrão (talvez se pudesse falar aqui em princípios, do ponto de vista chomskyano) da qual derivariam diversos dialetos (parâmetros - idem à observação anterior), mas diversos modos de falar que, nos seus pontos de contato, definiriam a língua maior. Logo, as constantes de uma língua não seriam pré-dadas para se materializarem em variações, mas seriam abstraídas das diversas variantes que ocorrem no discurso partilhado pela comunidade de falantes - as variações paramétricas definiriam os princípios, que não teriam existência prévia. 
Um modelo capaz de compreender a linguagem como entendida pelos autores não pode partir do pressuposto que exista uma linguagem feita, constantes que se materializam, mas uma linguagem em se fazendo, uma linguagem dinâmica e viva. Ou, citando Carlos Franchi (1992), um modelo capaz de interpretar a linguagem como atividade constitutiva, como meio constitutivo, não só para o meio (ou contrato) social, mas para o próprio falante enquanto sujeito e para a própria linguagem como atividade auto-renovável. Em resumo, um modelo capaz de compreender o devir da linguagem. Essa concepção de linguagem está presente no trabalho de diversos autores e de diversas correntes, desde os funcionalistas do Círculo de Praga (em especial, lembrando as "funções da linguagem", de Roman Jakobson), até em trabalhos mais recentes, como os de Searle, Grice e Halliday, que têm em comum o fato de aceitarem como regra que o fenômeno da significação não pode ser explicado somente pela estrutura da língua, mesmo que se pense em propriedades formais universais, porque a significação ultrapassa os limites impostos por esse tipo de análise que não considera as intenções de comunicação como elemento decisivo para a análise da linguagem. Desta forma, qualquer expressão lingüística tomada fora de seu contexto de produção, para eles, perde o seu valor de significação (ou, pelo menos, o valor exato), pois, isoladamente, as expressões da língua são ambíguas. Ou seja, somente a análise do contexto poderia reduzir o leque polissêmico das expressões lingüísticas.

Para Brown (1995), em seu texto - Speakers, listeners and communication: explorations in discourse analyses, as palavras possuem um sentido ambíguo que somente pode ser esclarecido através do contexto. Isso quer dizer que somente através do estudo do momento de enunciação é que podemos precisar como e de fato o caráter polissêmico da linguagem está sendo explorado pelos falantes. Muitos já tentaram eliminar esse caráter polissêmico por considerá-lo um problema semântico - e de fato pode ser. No entanto, é justamente a polissemia que torna a linguagem capaz de ser o material apropriado para o discurso. O que muitos semanticistas pretendem é justamente abstrair a linguagem de qualquer influência humana (já que imperfeita) para que a significação possa ser automaticamente processada. Já para a Pragmática, estão nesta "imperfeição" todos os instrumentos para a decisão sobre qual é a verdadeira interpretação para um enunciado porque é o estudo do contexto, do momento e da intenção, entre outros fatores (na maioria extralingüísticos), que irão determinar o valor semântico de uma expressão.

No entanto, Franchi afirma que as abordagens funcionalistas, que entendem a linguagem apenas como instrumento de comunicação e concebem a sua "funcionalidade" somente em relação às situações de uso social, também são limitadas porque acabam deixando de lado o seu caráter autônomo - entendido aqui como o processo que ocorre no interior do indivíduo e mais, no próprio interior da linguagem.

Talvez o maior inspirador de Franchi tenha sido Humboldt, para quem a linguagem serve primeiramente como instrumento constituidor das experiências para depois ser o meio de transmiti-las para os outros seres: "por meio da linguagem o homem 'dá forma' ao mesmo tempo a si mesmo e ao mundo, ou melhor, torna-se consciente de si mesmo, projetando um mundo no exterior". Assim, define a linguagem como atividade constitutiva, como meio constitutivo, não só 
para o meio (ou contrato) social, mas para o próprio falante enquanto sujeito e para a própria linguagem como atividade auto-renovável. Desse 'ponto de vista, não se pode apenas falar na linguagem enquanto meio pelo qual os homens se comunicam uns com os outros, como o fazem os funcionalistas; também não se pode pensar a linguagem simplesmente como um sistema formal, composto por léxico e regras ou por categorias e esquemas recursivos, como pretendem aqueles que defendem a homogeneidade da linguagem, mas quase como uma "entidade" metafísica que, ao mesmo tempo que é utilizada pelo indivíduo como meio de comunicação, usa o indivíduo para a sua própria reafirmação; indivíduo que, por sua vez, irá novamente utilizá-la, agora como forma de auto-definição e de definição de um mundo que será exteriorizado pela linguagem e, simultaneamente, introjetado também através da linguagem para dentro de si e da própria linguagem, constituindo-se um processo dinâmico em cadeia de constante expressão, retomada e renovação.

Justamente nesse processo dinâmico de constante confirmação/renovação reside o, talvez, problema central da linguagem: a sua indeterminação semântica ou, em outras palavras, a sua inegável característica de sempre poder significar coisas novas num engendramento "criativo" que toma o já existente e o reelabora, devolvendo ao mundo, através de si própria, novas significações que se juntarão às já existentes, ampliando a base sobre a qual o sujeito se debruçará (ou se apoiará) para "fabricar" novos sentidos indefinidamente.

A Linguagem vista assim, como atividade constitutiva, exige mecanismos de análise que não são os distribucionais ou formais, mas também não são os funcionais porque ambos são limitados a partes da linguagem: os primeiros às regras gramaticais e semânticas de um universo homogêneo e fechado e os últimos ligados mais às intenções do falante do que à linguagem.

Bakhtin (1997) abordou a questão da importância do entendimento de uma noção ampla de discurso, visto por ele como "a língua em sua integridade concreta e viva..." (p. 181), para a análise literária. Apesar de o seu objetivo ser o estudo de aspectos relativos ao discurso na obra literária, as suas reflexões ultrapassam os limites da teoria da literatura e confundem-se com reflexões que seriam apropriadas aos estudos de uma lingüística abrangente e não reducionista, que ele chama de metalingüística, diferente da lingüística estruturalista, de inspiração sausseriana, praticada na época.

Aliás, é importante lembrarmos que a lingüística que ele conheceu e abordou nesse texto é uma lingüística ainda muito distante das idéias correntes da lingüística textual de hoje, uma lingüística pré-pragmática que ainda estava muito longe de abordagens como as dos atos da fala, de Grice, ou das regras do discurso, de Ducrot. Essas abordagens também não dão conta do discurso, como pretendia Bakhtin, mas estão muito mais próximas do que estava qualquer abordagem estruturalista de sua época. Essas abordagens, segundo ele, eram incapazes de uma análise acurada de uma obra polifônica, como a de Dostoievski, por exemplo, porque sua preocupação (ou o seu limite de análise) não ultrapassava o aspecto composicional, ou seja, a forma da linguagem. A análise lingüística, vista assim, seria capaz de perceber os diversos estilos ou até falares, mas não as diversas vozes - justamente o que interessa em uma análise 
centrada no discurso - o que acabava por propiciar uma análise equivocada, pois com certeza atribuiria a um texto monofônico com diversos falares um caráter muito mais diversificado e "rico" do que atribuiria a um romance produzido num só estilo de linguagem, embora com diversas vozes.

O seu interesse maior estava nas relações dialógicas existentes entre os discursos, relações estas que são extralingüísticas, não podendo, portanto, serem estudadas pela lingüística, já que "aquela" lingüística tinha como maior interesse as relações de oposição existentes no sistema da língua. Uma língua abstraída do uso concreto da sociedade, o que impedia qualquer possibilidade de análise lingüística do discurso, pois esse "discurso" se faz de uma linguagem inatingível para as análises lingüísticas, linguagem esta que "só vive na comunicação dialógica daqueles que a usam" (p. 183). Comunicação dialógica que precisa da língua e dos seus aspectos lógicos e semânticos para poder ser realizar, mas que jamais poderá ser reduzida apenas a estes aspectos, pois, para realizar-se, precisa ser discurso de um autor e superar os limites próprios da língua, ou seja, os limites lógicos e semânticos estudados pela lingüística.

A oposição entre o que os lingüistas de tradição formalista e os que seguem uma orientação ligada ao discurso, como Bakhtin, ou até humanista como Humboldt e Franchi talvez possa ser bem exemplificada por um texto que Theodor Adorno (1994) escreveu sobre o ensaio, defendendo-o como forma de expressão científica, ao contrário do pensamento corrente que 0 considera como uma forma de expressão menos formal e científica. Ele defende a importância do ensaio enquanto forma de expressão humana ao mesmo tempo que critica aqueles que o definem como uma forma estigmatizada de expressão científica.

As críticas em relação ao ensaio acontecem porque ele não se enquadra naquilo que os manuais de redação científica prescrevem como a forma correta de manifestação subordinada a preceitos centenários. A redação técnica apresenta uma ordem imposta há muito tempo para que os textos científicos sejam definidos e creditados como tal. Eles precisam passar por um processo de "referendamento", isto é, precisam apresentar referências já afirmadas sobre o assunto, precisam partir de um ponto conhecido e aceitável pela comunidade científica, precisam redizer aquilo que já foi dito ou reafirmar a teoria e os pressupostos defendidos por uma ciência.

Segundo Adorno, o ensaio ainda guarda uma "disposição juvenil" para violar os limites impostos pelo conhecimento científico, ousando ir mais longe e abordar assuntos de forma opinativa ou mesmo emitir opiniões sobre um objeto cujos limites ainda não foram cientifica ou teoricamente delimitados.

O ensaio, enquanto discurso, é uma expressão do sujeito (e talvez por isso mesmo seja discurso), o que subverte a máxima das ciências deterministas que sempre pretenderam uma linguagem que não carregasse consigo as marcas nefastas da subjetividade, como se de fato houvesse o risco de que todo o pensamento positivista desmoronasse a partir dessa manifestação ou como se fosse possível eliminar a subjetividade de um sujeito/cientista que, 
enquanto Ser, é inerentemente subjetivo.

A necessidade de generalização das concepções nas ciências tenta afastar qualquer traço de individualidade - mesmo as ciências sociais procuram uma maneira adequada para a descrição do social sem que essa precise passar pelo individual. O indivíduo, quando aparece, sempre será uma estrutura representativa, um tipo e não um ser completo e fragmentado. A forma de descrição deste indivíduo prototípico deverá também ser típica e não individual. Daí a necessidade e a luta para separar a ciência das artes como coisas antitéticas e inconciliáveis.

O ensaio é uma forma de resistência a essa tendência porque o seu lugar talvez esteja justamente entre ciência e arte. Neste caso, poderíamos dizer que o ensaio enquanto forma é o paradoxo que aproxima os dois pólos. Meio termo entre a ciência que se pretende isenta e o sujeito que jamais será isento, entre o conhecimento e a imaginação.

A vida do ensaio se dá no conflito, no sonho que não pode ser controlado ou aprisionado. É o meio de expressão que permite ao homem ser sujeito integrado à história de seu tempo e de seu lugar mesmo sem saber ou precisar saber qual é a verdade essencial. É o meio pelo qual o homem pode exprimir a sua verdade (ou o que ele acredita ou sente ser verdade) sem precisar arrastar uma cadeia infindável de discursos institucionalizados para corroborar o seu pensamento (como faz o presente texto, por exemplo). O ensaio, ao contrário, estaria mais no terreno do homem comum (o qual, teimoso, também pensa, além de sentir e viver), fora, portanto, das supervalorizadas e "isentas" instâncias acadêmicas, onde o sistemático vale muito mais que o criativo.

Da mesma forma como o ensaio pode ser a forma de livre expressão, é imprescindível hoje, que os estudos da linguagem (e a ciência de maneira geral) reservem um espaço para o livre pensamento, não a mera especulação, mas a cogitação, no sentido latino mesmo do verbo cogitare, "pensar", porque pensar os fatos da linguagem com criatividade, filosoficamente, não implica em absoluto que o pesquisador estará devaneando ou falando qualquer absurdo, mas que ele pode expressar livremente o que pensa sem a obrigação de referendar o seu pensamento no pensamento do outro porque afinal, no pensamento de cada um já está o pensamento de todos os outros com os quais tomamos contato. No discurso de cada ser estão presentes os discursos de uma coletividade de seres que se expressaram através do discurso que já fazia parte da essência da sociedade antes mesmo que eles se expressassem. Discurso é história e o levantamento de qualquer hipótese científica é o produto histórico-discursivo de uma sociedade que pensa e se expressa, que cria e desenvolve, que caminha sempre assentada no fazer anterior e se arriscando no devir. Aí justamente está o lugar do ensaio e do livre pensamento: no devir do produto científico, antes que ele seja ciência, quando ele ainda é livre das amarras dos saberes canônicos. 
Referências bibliográficas

ADORNO, T. O ensaio como forma. In COHN, G. (org.) Theodor W. Adorno.

São Paulo: Ática, 1994.

BAKHTIN, M. Problemas da Poética de Dostoiévski. Rio: Forense-Universitária, 1997.

DELEUZE, G. \& GUATTARI, F. Mil Platôs: capitalismo e esquizofrenia. vol 2. Rio de Janeiro: Editora 34, 1995.

FRANCHI, Carlos. Linguagem: Atividade Constitutiva. In Cadernos de Estudos Lingüísticos nํ⒉ 22. Campinas: Unicamp/ IEL: 1992.

GILMAN, S. L. Editor. Friedrich Nietzsche on rhetoric and language. UK : Oxford University Press, 1997.

HUMBOLDT, W. On Language: on the diversity of human language construction and Its influence on the mental development of the human species. UK : Cambridge University Press, 1988.

POSSENTI, Sírio. O dado dado e o dado dado. In PEREIRA DE CASTRO, Maria Fausta. O método e o dado no estudo da linguagem. Campinas: Ed. Da Unicamp, 1996. 